\title{
Degradation of Endosulfan by Mixed Bacterial Cultures Enriched from Endosulfan Contaminated Soils of Southern India
}

\author{
Sarah Sunitha, V. KrishnaMurthy, and Riaz Mahmood
}

\begin{abstract}
Endosulfan is a characteristic pesticide having both chlorine and sulphur as functional groups, effective in controlling a large spectrum of pests. It is sprayed as contact insecticide on food crops. Residues of $\alpha$ and $\beta$ endosulfan have varying half life and persist in air, water and soil along with their degradation products. The present study aimed at delineating endosulfan residues in soil, representing samples drawn from agricultural fields during winter season. The samples after pre-treatment were subjected to enrichment of the residues. The residues were estimated by GC-ECD method. The concentration of $\alpha$ endosulfan ranged from $0.1 \mathrm{mg}$ to 29 $\mathrm{mg} / \mathrm{Kg}$, the levels of $\beta$ Endosulfan ranged from $0.1-167 \mathrm{mg} / \mathrm{kg}$, and that of Endosulfan sulphate ranged from 0.12-27 $\mathrm{mg} / \mathrm{Kg}$ respectively. This study once again proves the highly persistant nature of the residues of endosulfan in soil and hence the need to find measures to remove them from the environment.

The microorganisms present in this soil were found to possess the ability to degrade endosulfan as they are chronically exposed to it. Up to $70 \%$ of endosulfan and $100 \%$ of Endosulfan sulphate degradation were observed. Hence, organisms isolated from endosulfan contaminated soils by the process of enrichment can be used as bio remediating agents for soil and water.
\end{abstract}

Index Terms-Endosulfan, persistence, enrichment.

\section{INTRODUCTION}

Endosulfan (1, 2, 3, 4, 7, 7-hexachlorobicyclo (2.2.1)-2-heptene-5, 6-bisoxymethylenesulfite) is a pesticide widely used all over the world, since 1954 when it was first released for commercial use [1]. India is one of the largest consumers of pesticides in South Asia [2]. According to the Indian Chemical Council, it is used extensively to control pests in a wide range of crops like cereals, tea, coffee, cotton, cashew, fruits, and vegetables.

Commercial Endosulfan is synthesized as a mixture of two isomers approximately $70 \% \quad \alpha$-Endosulfan and $30 \%$ $\beta$-Endosulfan. Endosulfan has been detected in the atmosphere, soil, sediments, surface water, and rain water

Manuscript received December 01, 2011. This work was supported in part by the University Grants Commission, Government of India. (Grant number MRP(S)-704/10-11/KABA037/UGC-SWRO).

V.Krishnamurthy and Sarah Sunitha are with Department of Biotechnology, PES Institute of Technology, BSK III Stage, Bangalore-560085, India (e-mail: profvkm55@yahoo.com, Sarah Sunitha: sarahjohn125@gmail.com).

Riaz Mahmood is with Department of Biotechnology and Bioinformatics, Kuvempu University, Shankarghatta, Shimoga-577451 India (e-mail: riaz_sultan@yahoo.com). and food materials [3].

Due to its hydrophobic nature, Endosulfan tends to get adsorbed to soil particles, resulting in persistence [4], [5]. The rate of degradation of Endosulfan is rather low and often results in the formation of Endosulfan sulphate which is an oxidative metabolite shown to be as toxic and persistant as the parent compound.

Endosulfan is known to be an endocrine disruptor and a genotoxin [6], [7]. Because of its persistence in the environment for a long time, and its toxicity, endosulfan contamination in the environment is of great concern.

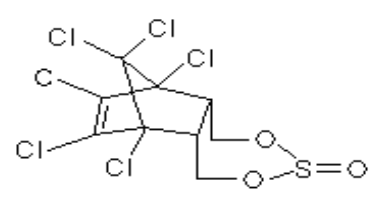

$\alpha$-Endosulfan

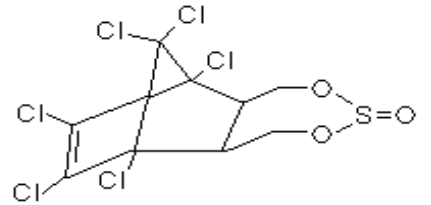

$\beta$-Endosulfan<smiles>O=S1(=O)OCC2C(CO1)[C@@]1(Cl)C(Cl)=C(Cl)[C@]2(Cl)C1(F)Cl</smiles>

Fig. 1. Structure of Endosulfan isomers and Endosulfan sulphate

Endosulfan contaminated soil can be a rich source of bacteria that can possess the ability to degrade this persistant molecule. Endosulfan degradation has been reported by various microorganisms including bacteria like Pseudomonas aeruginosa [8], Arthrobacter sp [9], Mycobacterium Sp. Strain ESD [10] and also mixed cultures of bacteria [11], [12].

\section{MATERIALS AND MethodS}

\section{A. Soil Sampling}

Soil sampling was done by the quartet method. A 10 square feet area was cleaned and demarcated into 4 quartets. About $1 \mathrm{~kg}$ of the soil was collected from $0-15 \mathrm{~cm}$ depth from 2 opposite quartets into a plastic trough. This was then mixed well and again divided into four quartets. The soil from opposite quartets was collected and was further reduced to $1 / 2$ $\mathrm{kg}$ and stored in cotton bags and then placed in polythene covers. Samples were collected from at least four different 
parts of the same field.

TABLE I: SOIL SAMPLING SITES

\begin{tabular}{|r|l|l|}
\hline \multicolumn{1}{|c|}{ Field } & Geographical area & $\begin{array}{l}\text { Standing } \\
\text { Crop }\end{array}$ \\
\hline 1. & $\begin{array}{l}\text { Gejjagaaraguppe, Ramanagara, } \\
\text { Karnataka }\end{array}$ & $\begin{array}{l}\text { Bengal } \\
\text { gram }\end{array}$ \\
\hline 2. & Field 1,Baalupete, Hassan, Karnataka & Coffee \\
\hline 3. & Field 2, Baalupete, Hassan, Karnataka & Coffee \\
\hline 4. & Hommagarahalli, HD Kote, Mysore & Paddy \\
\hline 5. & Field 1, Badiyadka, Kasargod, Kerala & Cashew \\
\hline 6. & Field 2, Badiyadka, Kasargod, Kerala & Cashew \\
\hline
\end{tabular}

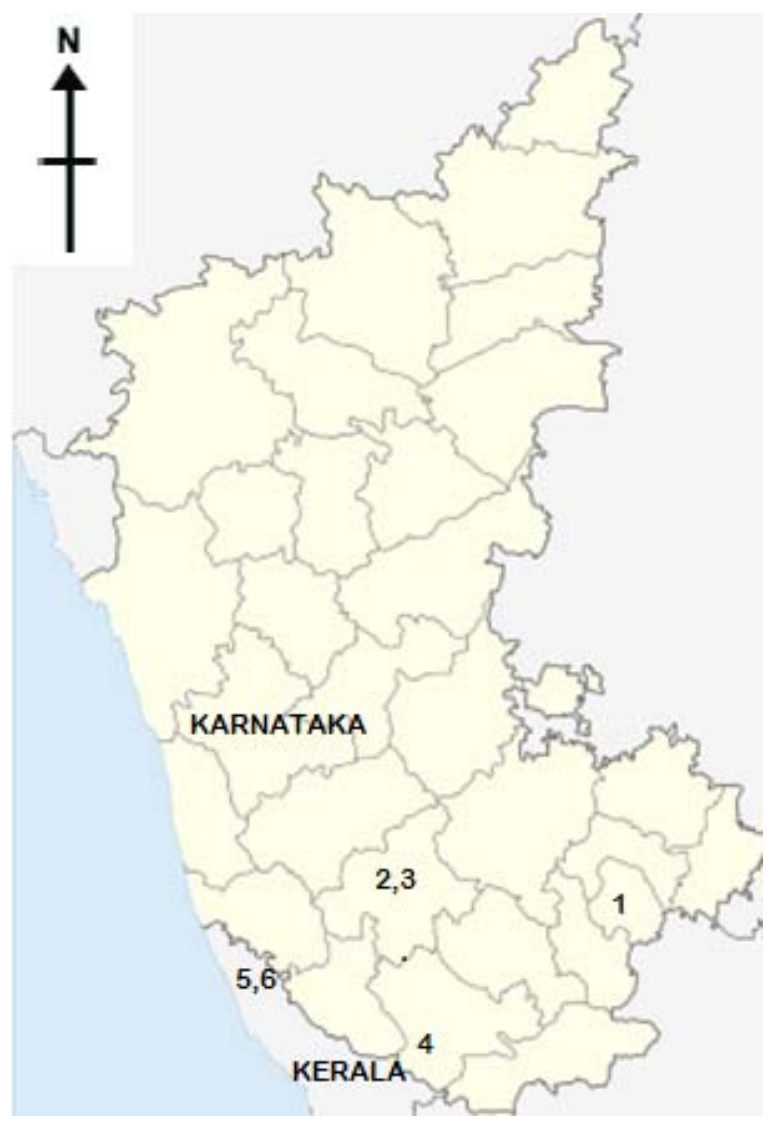

Fig. 2. Sampling sites in South India

The sampling sites were identified in consultation with the Agricultural Officers, pesticide retailers and local farmers. Totally six agricultural fields were identified where there was a history of application of Endosulfan.

Fields 1-4 are located in the state of Karnataka and have seen regular application of endosulfan. Fields 5 and 6 are

located in Badiyadka, in Kasargod district of neighbouring state of Kerala. This region is a predominantly Cashew growing area and has seen aerial application of Endosulfan for many years, though it has now been discontinued.

\section{B. Pre-Processing and Preparation of Residues from Soil}

Upon receipt to the lab, the soil sample was air dried at room temperature, powdered in a pestle and mortar and sieved through a $2 \mathrm{~mm}$ sieve and stored at $4{ }^{\circ} \mathrm{C}$ till further analysis. The slightly modified method adopted from [13] was used for the extraction of the residues. 5 grams of the soil was soaked overnight in $40 \mathrm{ml}$ of Hexane: acetone (80:20), in a $250 \mathrm{ml}$ sealed conical flask. The flask was then shaken in an orbital shaker at $70 \mathrm{rpm}$ at room temperature for about 2 hours. The solution was filtered through filter paper and the soil was re-extracted twice with $30 \mathrm{ml}$ of Hexane \& acetone (80:20). The extract was passed through a column of $5 \mathrm{~g}$ of Florisil layered with $2 \mathrm{~g}$ of sodium sulphite. The extract was then concentrated in a rotary vacuum evaporator and reduced to $0.5 \mathrm{ml}$.

\section{Gas Chromatographic Analysis}

The residues were analysed by Gas Chromatography(GC) (Agilent) system fitted with an ECD detector on a DB 1701 column (30 $\mathrm{m} \times 0.25)$ with Nitrogen as the carrier gas with a flow rate of $1 \mathrm{ml} /$ minute. The oven temperature was $280^{\circ} \mathrm{C}$, injection temperature was $290^{\circ} \mathrm{C}$ and the detector temperature was $320^{\circ} \mathrm{C}$. Technical grade $\alpha$ Endosulfan, $\beta$ Endosulfan and Endosulfan sulphate obtained from Sigma Aldrich India were used in all experiments. HPLC grade solvents were procured from Merck chemicals (India). All chemicals were of analytical grade.

\section{Enrichment of Bacterial Cultures from Soil}

15 grams of composite soil sample from each geographical location was wetted with sterile water and mixed with $2 \mathrm{mg}$ of technical grade Endosulfan and kept in the dark for 1 month. $1 \mathrm{~g}$ of this sample was then transferred to $100 \mathrm{ml}$ Enrichment medium containing $20 \mathrm{mg} / \mathrm{L}$ of Endosulfan and incubated at $28 \pm 2{ }^{0} \mathrm{C}$ at $120 \mathrm{rpm}$ [14]. The culture so obtained was further subcultured every 15 days and after 9 rounds of subculture, they were used for analyzing their degradative potential. These cultures were designated S1, S2, S3, S4, S5 and S6.

\section{E. Study of Ability of the Enriched Cultures to Degrade Endosulfan and Endosulfan Sulphate}

$25 \mathrm{ml}$ of enrichment medium containing $20 \mathrm{mg} / \mathrm{L}$ of Endosulfan was inoculated with S1, S2, S3, S4, S5 and S6 cultures to obtain an initial absorbance of 0.1 at $600 \mathrm{~nm}$ in $100 \mathrm{ml}$ conical flasks. These flasks were incubated at $28 \pm 2$ ${ }^{0} \mathrm{C}$ at $120 \mathrm{rpm}$. Similar set of experiment was done with medium containing $40 \mathrm{mg} / \mathrm{L}$ Endosulfan sulphate. Control medium without inocula were maintained in parallel. After incubation for 14 days, the culture was extracted twice with equal volumes of ethyl acetate and passed on a column of 12 $\mathrm{g}$ of anhydrous Sodium sulphate. The column was eluted with ethyl acetate and dichloromethane and concentrated as earlier. The residues were analyzed using GC.

\section{RESULTS AND DISCUSSION}

\section{A. Level of Endosulfan Residues in Soil}

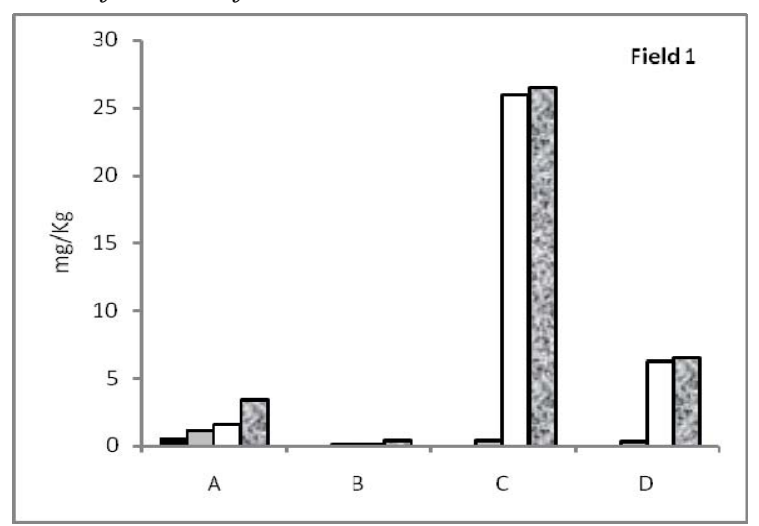

(a) 


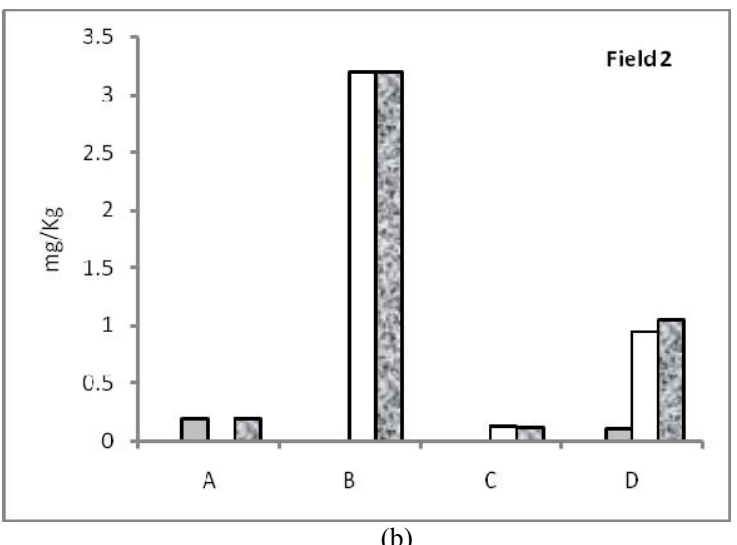

(b)

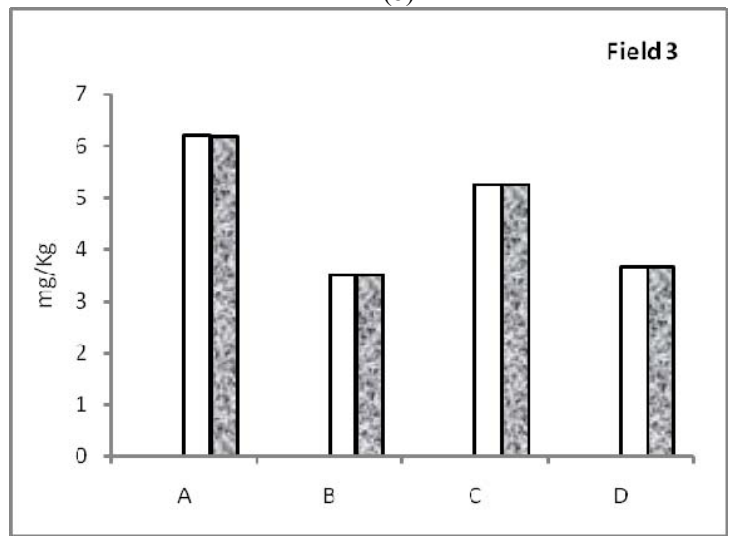

(c)

$\alpha$-endosulfan ( $\mathrm{mg} / \mathrm{Kg}$ )

$\square \beta$-endosulfan ( $\mathrm{mg} / \mathrm{kg}$ )

$\square$ endosulfan sulphate $(\mathrm{mg} / \mathrm{kg}$ )

$\square$ total endosulfan $(\mathrm{mg} / \mathrm{kg}$ )

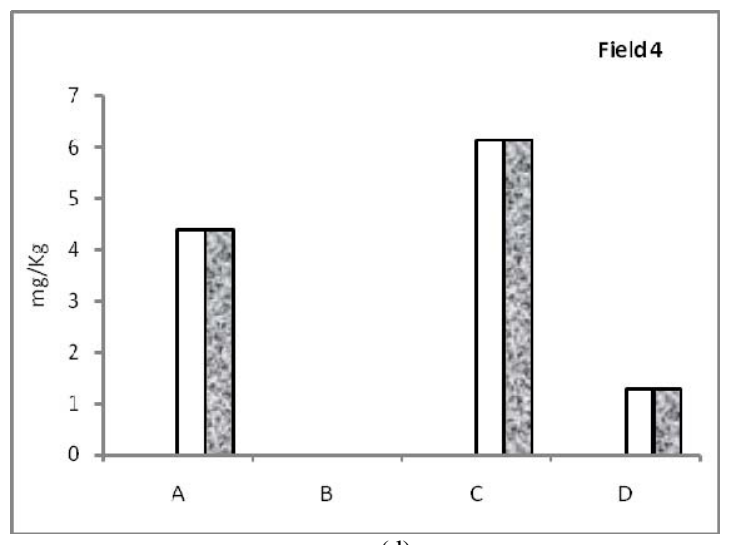

(d)

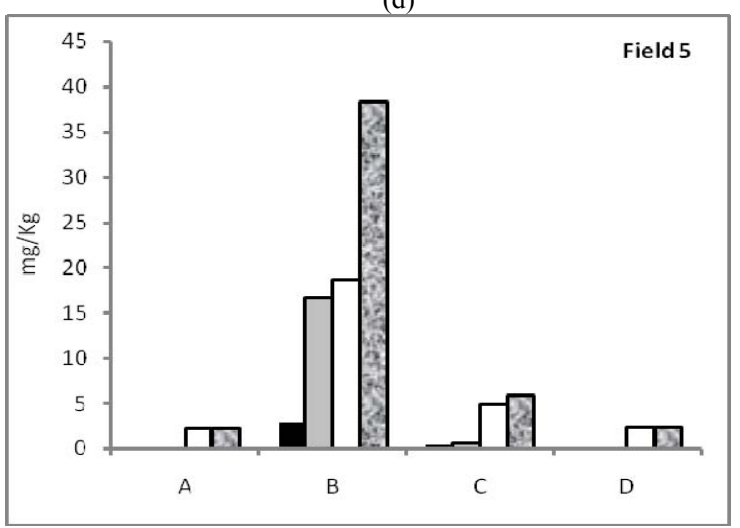

(e)

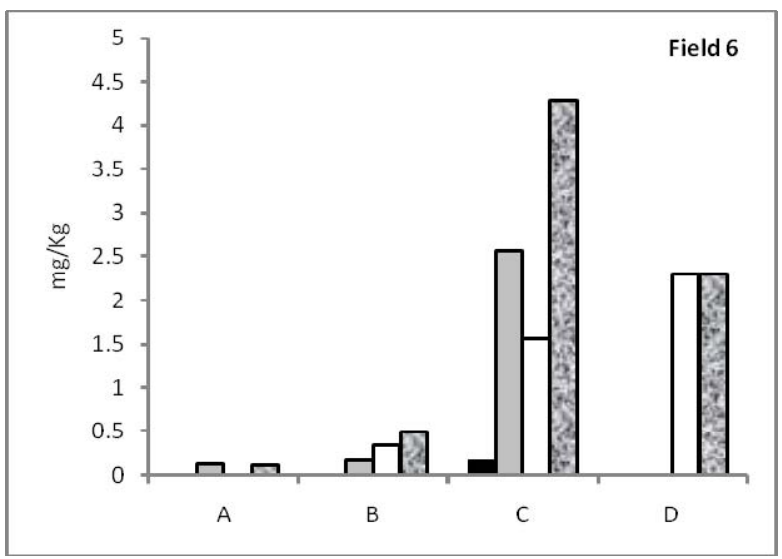

(f)

Fig. 2. (a)-(f). Levels of $\alpha$ Endosulfan, $\beta$ Endosulfan, Endosulfan sulphate and Total Endosulfan in 4 samples of soil $(A, B, C, D)$ obtained from fields $1-6$.

The retention time for $\alpha, \beta$ and Endosulfan sulphate was found to be $41.94,46.64$ and 49.82 minutes respectively. The detection limit was $50 \mu \mathrm{g} / \mathrm{L}$.

The levels of $\alpha$ Endosulfan ranged from $0.1 \mathrm{mg}$ to 29 $\mathrm{mg} / \mathrm{Kg}, \quad \beta$ Endosulfan $\mathrm{mg} / \mathrm{Kg}$ from $0.1-167 \mathrm{mg} / \mathrm{kg}$, and Endosulfan sulphate from $0.12-187 \mathrm{mg} / \mathrm{Kg}$. In locations 1 and 5, high amounts of $\alpha$ and $\beta$ Endosulfan are seen compared to the other locations. Endosulfan sulphate could be seen in considerable quantities in all the locations, owing to its highly persistant nature. Other reports of endosulfan residue levels in India in paddy fields are $\alpha$ endosulfan- 0.98 $\mathrm{mg} / \mathrm{Kg}, \quad \beta$ Endosulfan $-6.39-0.800 \mathrm{mg} / \mathrm{Kg}$ and Endosulfan sulphate- $11.8-2.2 \mathrm{mg} / \mathrm{Kg}[13]$. In the Tea grown areas of West Bengal, $\alpha$ Endosulfan ranged from $0.007-0.081 \mathrm{mg} / \mathrm{Kg}$, $\beta$ Endosulfan ranged from $0.008-0.256 \mathrm{mg} / \mathrm{Kg}$, and Endosulfan sulphate from $0.055-0.095 \mathrm{mg} / \mathrm{kg}$ [15].

Our study reports the highest levels of Endosulfan residues from the Southern parts of India. The persistence of the residues of endosulfan that cause pollution in soil are dependent on various factors like soil type, particle size of soil particles, rainfall etc [16]. Other factors can also be due to existing meteorological conditions, soil quality and spraying profile in that area. Endosulfan can contaminate the soil and water in the vicinity of the fields where it is applied by one of the following methods-spray drift, vapour transport, dust transport, and runoff pathways [17]. Under anaerobic conditions, the half life of Endosulfan in water is reported to be 1-6 months [18]. In soil, the half lives of $\alpha, \beta$ and total endosulfan under aerobic conditions has been reported to range between 12-39, 108-264 and 288-2241 days respectively [19]. 


\section{B. Endosulfan Degradation by Enrichment Cultures}

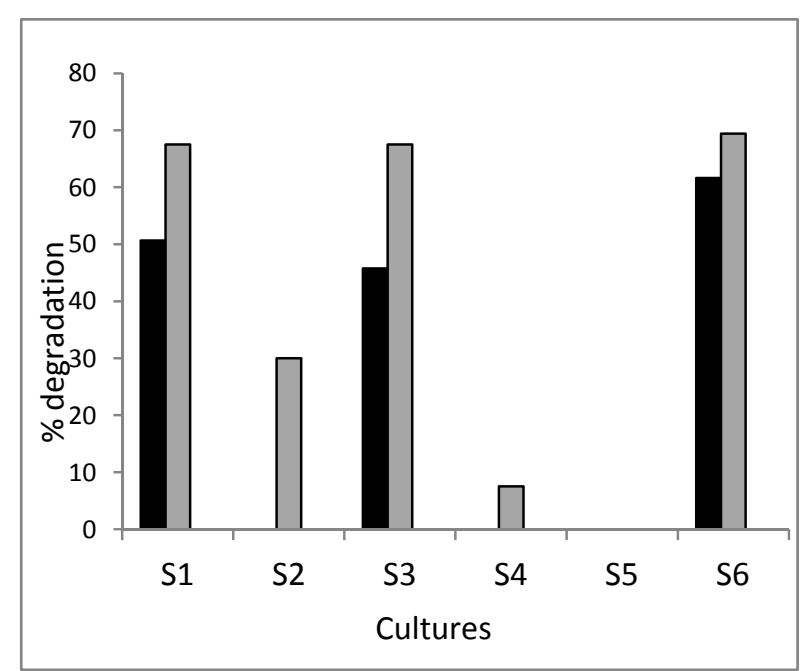

- $\alpha$ Endosulfan $\square \beta$ Endosulfan $\square$ Total Endosulfan

Fig. 3. Percent degradation of Endosulfan by enrichment cultures S1-S6.

Of the six cultures obtained by enrichment, cultures S1, S3 and S6 showed degradation of Endosulfan with S6 showing highest degradation of $67 \%$ of the spiked Endosulfan. All the three cultures degraded more of $\beta$ isomer than $\alpha$ isomer of endosulfan. Culture S1 showed the presence of Endosulfan sulphate, Endosulfan alcohol was detected in S3 and both of these were detected in S6. The cultures S2 and S4 showed little degradation while no degradation was observed in S5, though it contained large amount of residues.

\section{Endosulfan Sulphate Degradation by Enrichment Cultures}

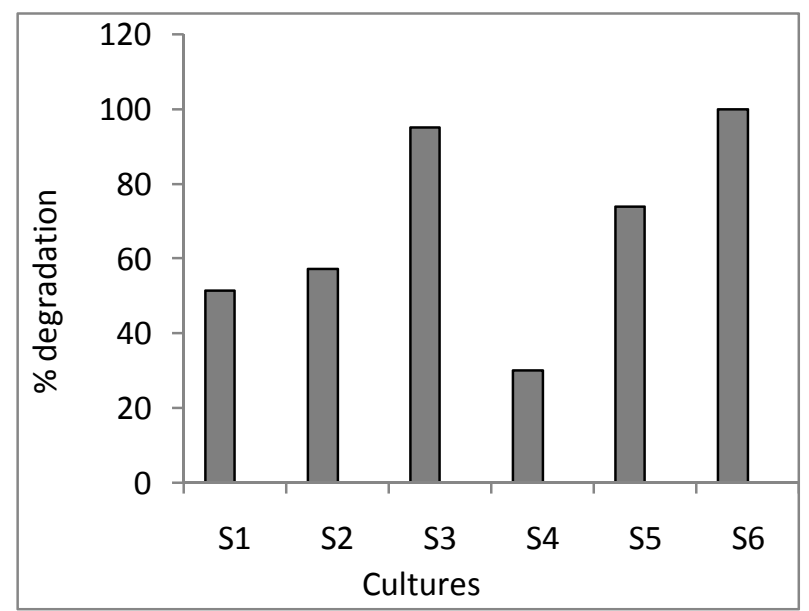

Fig. 4. Percent degradation of endosulfan sulphate by enrichment cultures S1-S6.

The cultures also exhibited considerable ability to degrade Endosulfan sulphate. This is of importance since Endosulfan sulphate is more persistant and toxic than Endosulfan isomers. In cultures S3 and S6, 95 and 100\% degradation was observed. All the cultures were able to degrade Endosulfan sulphate to varying extents. Endosulfan alcohol was the major metabolite detected in all the cultures. Cultures obtained by enrichment have been shown to degrade Endosulfan not only in culture media but also in laboratory scale reactors as well as pilot scale reactors. In different soil types, the mixed culture degraded more than $95 \%$ of endosulfan in a period of 1 month while in pilot scale reactors, about $86 \%$ degradation was observed after 56 days [20], [21].

Chronic exposure to endosulfan in humans can cause congenital deformities, long term brain damage, epilepsy, autism, delayed sexual maturity, early menarche, and cerebral palsy [22]-[26]. Endosulfan bioaccumulation can also be seen in a number of terrestrial and aquatic animals. Hence, regulations in the usage of Endosulfan, alternative solutions for pest management and bio remedial measures for the removal of endosulfan residues from the soil are issues that necessitate immediate attention. The bacterial cultures isolated in this study can be further characterised and used for the removal of endosulfan and its metabolites from soil and water.

\section{ACKNOWLEGDMENT}

Financial support is acknowledged in the unnumbered footnote on the first page. The authors thank the Management of P.E.S Institute of Technology, Bangalore, India, for their support and encouragement in undertaking this work.

\section{REFERENCES}

[1] H. Maier-Bode, "Properties, effects, residues and analytics of the Insecticide endosulfan," Residue Rev. vol. 22, pp.1-44, 1958.

[2] N. P. Agnihotri, Pesticide: Safety evaluation and Monitoring. Published in All India Co-ordinated project (AICRP) on pesticide residues. Indian Agricultural Research Institute, New Delhi, India, pp. 132-142. 1999.

[3] US Department of Health and Human Services. Toxicological profile of Endosulfan. Agency for toxic substance and disease registry, Atlanta. 1990

[4] D. M. R. Rao and A. S. Murthy, "Persistence of Endosulfan in soils," Journal of Agricultural and Food Chemistry, vol. 28, pp. 1099-1101, 1980.

[5] A. M. Leung, D.M.McDonough, and C.D.West, "Determination of endosulfans in soil/sediment samples from point Mogu, Oxnard, CA using capillary Gas Chromatography/ mass selective detection (GC/MSD)." Environmental Monitoring and Assesment. Vol.50, pp. 85-94, 1998

[6] M. F. Fernandez, "Human exposure to endocrine-disrupting chemicals and prenatal risk factors for cryptorchidism and hypospadias: a nested case-control study." Environmental Health Perspectives. vol. 115, no. 1, pp. 8-14, Dec 2007.

[7] Y. Lu, "Genotoxic effects of alpha-endosulfan and beta-endosulfan on human HepG2 cells." Environmental Health Perspectives. vol. 108, no. 6, pp. 559-61, June 2000.

[8] M. Arshad, S. Hussain, and M. Saleem, "Optimization of environmental parameters for biodegradation of alpha and beta endosulfan in soil slurry by Pseudomonas aeruginosa." Journal of Applied Microbiology, vol. 104, no. 2, pp 364-370, Feb 2008.

[9] K. M. Weir, T. D Sutherland, I. Horne, R. J. Russel, and J. G. Oakshott, "A single monooxygenase Ese is involved in the metabolism of the organochlorides Endosulfan and Endosulfate in an Arthrobacter sps." Applied and Environmental Microbiology, vol. 72, No. 5, pp 3524-3530, May 2006.

[10] T. D. Sutherland, I. Horne, R. L. Harcourt, and R. J. Russel, J. G. Oaksshott, "Isolation and characterization of a Mycobacterium strain that metabolizes the insecticide Endosulfan," Journal of Applied Microbiology, vol. 93, pp. 380-389, 2002.

[11] T. D. Sutherland, K. M. Weir, M. J. Lacey, I. Horne, R. J. Russsel, and J. G. Oakshott, "Enrichment of a microbial culture capable of degrading endosulphate, the toxic metabolite of endosulfan," Journal of Applied Microbiology, vol.92, no. 3, pp. 541-548, 2002.

[12] M. Kumar and L. Philip, "Enrichment and isolation of a mixed bacterial culture for complete mineralization of endosulfan," Journal of Environmental Science and Health part B, vol.41, pp. 81-96, 2006. 
[13] R. Jayashree and N. Vasudevan, "Persistence and distribution of endosulfan under field conditions," Environmental Monitoring and Assessment. vol. 131, no. 1-3, pp. 475-87, 2007.

[14] T. D. Sutherland, I. Horne, M. J. Lacey, R. L. Harcourt, R. J. Russel, and J. G. Oakshott, "Enrichment of an Endosulfan degrading mixed bacterial culture," Applied Environmental Microbiology, vol. 66, no. 7, pp. 2822-8, 2000.

[15] A. Bishnu, T. Saha, D. Mazumdar, K. Chakrabarti , and A. Chakraborty "Assessment of the impact of pesticide residues on microbiological and biochemical parameters of tea garden soils in India," Journal of Environmental health and Science B, vol. 43, no. 8, pp. 723-31, Nov 2008.

[16] M. Zhou, Y. C. Li, P. Nkedi-Kizza, and S. K. OHair, "Endosulfan Losses through Runoff and Leaching from Calcareous Gravelly or Marl Soils," Vadose Zone Journal vol. 2, pp. 231-238, 2003.

[17] M. R. Roupach, P. R. Briggs, P. W. Ford, J. F. Leys, M. Muschal, B. Cooper, and V. E. Edge, "Endosulfan Transport: I. Integrative Assessment of Airborne and Waterborne Pathways," Journal of Enviromental Quality. vol. 30, pp. 714-728, 2001.

[18] ASTDR, Toxicological Profile for Endosulfan. Agency of Toxic Substances and Disease Registry, Atlanta, USA. 2000. http://www.atsdr.cdc.gov/toxprofiles/tp41.html

[19] GFEA-U, Endosulfan. Draft Dossier prepared in support of a proposal of endosulfan to be considered as a candidate for inclusion in the CLRTAP protocol on persistent organic pollutants. German Federal Environment Agency - Umweltbundesamt, Berlin. 2007.
[20] M. Kumar and L. Philip, "Bioremediation of endosulfan contaminated soil and water- optimization of operating conditions in laboratory scale reactors," Journal of Hazardous materials, vol. 136, no. 2, pp 354-364, Aug 2006.

[21] M. Kumar and L. Philip, "Biodegradatiom of endosulfan contaminated soil in a pilot scale reactor bioaugmented with mixed bacterial culture." Journal of Environmental Science and Health B, vol. 42, no. 6, pp 707-715, Aug 2007.

[22] D. R. Alexsandrowicz, "Endosulfan poisoning and chronic brain syndrome," Archives of Toxicology, vol. 43, pp. 65-8, Oct 1979.

[23] R. F. Quijano, Endosulfan Poisoning in Kasargod, Kerala, India:Report on a Fact-finding Mission. Pesticide Action Network Asia and the Pacific, Penang, 2002.

[24] H. Saiyed, A. Dewan, V. Bhatnagar, U. Shenoy, R. Shenoy, H. Rajmohan, K. Patel, R. Kashyap, P. Kulkarni, B. Rajan, and B. Lakkad, "Effect of endosulfan on male reproductive development." Environmental Health Perspectives vol. 111, no. 16, pp. 1958-62, Dec 2003.

[25] E. M. Roberts, P. B. English, K. J. Grether, G. C. Windham, L. Somberg, and C. Wolff, "Maternal residence near agricultural pesticide applications and autism spectrum disorders among children in the California Central Valley." Environmental Health Perspectives vol. 115, no. 10, pp. 1482-9, 2007.

[26] US EPA, Addendum to the Ecological Risk Assessment for Endosulfan, Memorandum to Special Review and Reregistration Branch. EPA-HQ-OPP-2002-0262-0063. Oct 31, 2007c. 